\title{
ALLAH MEMILIH BUMI MENJADI TEMPAT TINGGALNYA Refleksi Ekologis Atas Peristiwa Natal
}

\author{
Largus Nadeak*
}

\begin{abstract}
Abstrak
Perayaan Natal merupakan kesempatan bagi orang Kristen untuk merenungkan dan mengalami peristiwa inkarnasi ilahi. Allah menjadi manusia dan memilih bumi menjadi tempat tinggal-Nya. Bumi menjadi rumah bersama Allah Pencipta dengan manusia ciptaan dan ciptaan lain. Cara Fransiskus Assisi merayakan Natal yang melibatkan warga ekologis, menjadi inspirasi panggilan untuk orang beriman agar menjaga bumi rumah bersama dan melindungi penghuninya yaitu manusia, hewan, tumbuhan dan ciptaan lain. Dengan melindungi bumi dan penghuninya, manusia menghormati Pencipta, dan ciptaan berperan sakramental mentransparansikan Sang Pencipta. Agar bumi menjadi rumah bersama yang menyegarkan, manusia dipanggil untuk melakukan tindakan konkret di tempat dan di waktu masing-masing.
\end{abstract}

Kata-kata kunci: Allah, Natal, bumi, ciptaan, rumah, bersaudara, memelihara.

\section{Pengantar}

Perhatian pada bumi dan kondisinya semakin menonjol dewasa ini. Sebagian masyarakat semakin melihat dan sadar bahwa bumi dan isinya, antara lain tumbuhan, hewan makin punah serta tanah, air, dan udara menjadi kotor tercemar dan bahkan persediaan kekayaan bumi makin menipis oleh perbuatan manusia. Perbuatan pencemaran terhadap bumi dan isinya menyebabkan alam semesta semakin kehilangan sifat simbolis dan muatan sakramentalnya. ${ }^{1}$

* Largus Nadeak, Lisensiat dalam bidang Teologi Moral; lulusan Universitas Lateran, Italia; Dosen Teologi pada Fakultas Filsafat Unika St. Thomas, Sumatera Utara.

${ }^{1}$ Leondardo Boff, Jeritan Bumi, Jeritan Penderitaan (Medan: Bina Media Perintis, 2008), hlm. 271. 
Allah dalam diri Yesus memilih bumi menjadi tempat tinggal-Nya. "The earth was made to be the home of God"2 Di bumi Allah bertemu dengan manusia dan ciptaan lain. Pertemuan bermakna ini memberdayakan peran manusia untuk memelihara bumi dan isinya. Dengan memelihara bumi dengan baik, manusia dengan sendirinya menjaga dengan hormat keberadaan bersama Allah sang Penebus Dunia.

Sejak terjadi komunikasi Allah dengan manusia, Allah telah hadir di bumi, tetapi kehadiran-Nya semakin nyata pada saat inkarnasi yang dirayakan oleh orang Kristen secara khusus pada peristiwa Natal.

\section{Riwayat Inkarnasi}

Pemahaman tempat keberadaan Allah memiliki kisah menarik. Ada keyakinan bahwa Allah bertransendensi atas ciptaan (Pythagoreanisme), yang lain berkeyakinan bahwa Allah imanen dalam ciptaan-Nya (Panteisme). Ada pemahaman yang mengkombinasikan bahwa Allah transeden atas ciptaan-Nya dan sekaligus imanen di dalamnya (Panenteisme). Penganut Panenteisme mengatakan bahwa Allah berada di mana-mana (semua tempat) dan di kapan-kapan (semua waktu).

Pengalaman Yakub membantu penghayatan iman orang Kristen tentang kehadiran Allah di bumi. Dengan indah dilukiskan, "Ketika Yakub bangun dari tidurnya, berkatalah ia, 'Sesungguhnya Tuhan ada di tempat ini, dan aku tidak mengetahuinya.' Ia takut dan berkata, 'Alangkah dasyatnya tempat ini. Ini tidak lain dari rumah Allah, ini pintu gerbang surga.'" (Kejadian 28, 16-17). Namun peristiwa Natal bagi umat Kristen menjadi jelas bahwa Allah memilih bumi menjadi tempat tinggal-Nya. Peristiwa kehadiran Allah di bumi bersama ciptaan-Nya disebut inkarnasi.

Peristiwa inkarnasi memiliki riwayat yang memiliki ikatan kuat dengan tujuan inkarnasi tersebut. Thomas Aquinas mengatakan bahwa tujuan inkarnasi adalah untuk menghapus dosa. Sesuai alur pendapat ini, seandainya manusia tidak berdosa maka inkarnasi atau penjelaman Allah menjadi manusia tidak perlu. ${ }^{3}$ Menurut Jean Gallot, kalau kita membicarakan inkarnasi, "We must go back to God's initiative which

\footnotetext{
${ }^{2}$ Charles M. Murphy, At Home on Earth, Foundations for a Catholic Ethic of the Ecvironment (New York: Crossroad, 1989), hlm. 6.

${ }^{3}$ Pendapat Thomas Aquinas dalam Raidin Sinaga, "Cur Verbum Capax Hominis, Alasan Inkarnasi Sabda menurut St. Thomas Aquinas" dalam Logos, vol. 6, no. 1, Juni 2008, hlm. 23-24.
} 
commanded the action by which the Son of God lunched into the adventure of hauman life. The meaning of the whole economy of salvation is involeved in this exploration, and we can understand the bitter arguments among the theological schools regarding the motive for the Incarnation."4 Dalam alur pendapat Gallot ini, tujuan inkarnasi adalah agar orang beriman semakin memahami dinamisme kehadiran Allah yang tampak dalam Yesus. Dinamika ilahi menunjukkan bahwa Allah menjadi manusia agar manusia memahami Allah. Allah menyatakan kehadiran-Nya dengan cara manusiawi di bumi ini. ${ }^{5}$ "He is concretely God's presence on earth." 6

Agar manusia bisa berkomunikasi dengan Allah, dan manusia bisa bicara tentang kosmos sebagai tempat persekutuan Tritunggal Ilahi bersama ciptaan insani dan ciptaan lain, Allah sengaja memilih bumi ciptaan-Nya menjadi tempat-Nya.7 "It is neccessary to understad the humble condition of a servant that characterized Jesus'erthly life, in contrast to his glorious life. Only then can we realize what Jesus has been and what he will continue to be for the men and women involved this same earthly life." 8 "Jesus appeared on earth as the fruit and the fulfilment of God's promises of salvation. From the point of view of Bilbical research, it is primordial by reason of God's own revelation of himslef to the Jewish people. The man Jesus did not spring up in an indetermine human melieu; he was born within the bosom of the people who had entracted a covenant with the true God." 9

\section{Yesus Lahir di Tanah Betlehem}

Daerah Mediterania, secara khusus tanah Betlehem adalah tempat kelahiran dan saksi kegiatan Yesus Kristus. Allah yang Maha Kekal hidup di sejarah berlimit, Allah yang Maha Besar tinggal di bumi terbatas. Yesus lahir di waktu yang terbatas, dan di suku tertentu dengan silsilah satu suku yang jelas. Kenyataan historis ini menunjukkan bahwa Yesus hidup di alam semesta, di alam ciptaan Allah. Tempat Yesus lahir dan berkegiatan di daerah Mediterania,

4 Jean Gallot, Who is Christ?, a Theology of the Incarnation (Rome: Gregorian Uniersity Press, 1980), hlm.37.

${ }^{5}$ J. Gallot, Who is Christ?..., hlm. 38, 49-50.

${ }^{6} \mathrm{~J}$. Gallot, Who is Christ?,,',, hlm. 161.

7 Bernadeta Harini Tri Prasasti (ed), Lingkungan Hidup (Dokpen KWI: Jakarta 2014), hlm. 129.

8 J. Gallot, Who is Christ?..., hlm. 12.

${ }^{9} \mathrm{~J}$. Gallot Who is Christ?..., hlm 37. 
bermuatan pars pro toto. Walau Dia lahir di Betlehem dan berkegiatan di daerah terbatas dan tertentu yaitu di Mediterania, Dia nyata lahir dan berkegiatan di seluruh alam semesta. Dengan menyentuh Betlehem, Yesus juga menyentuh seluruh bumi; Dia berada dan berkegiatan di seluruh bumi serta menyentuh semua ciptaan. Hal ini membuktikan bahwa Allah ikut serta dalam sejarah kosmogenik sehingga sejarah manusia dan bumi bagian dari sejarah ilahi. ${ }^{10}$

Dengan inkarnasi Allah Pencipta turun ke tingkat ciptaan, dan dengan pilihan tersebut Dia menjadikan ciptaan berpartisipasi dialogis dalam hidup-Nya. Dengan inkarnasi Allah hidup dari hasil ciptaan-Nya sendiri. Dengan inkarnasi Allah menyatakan tindakan solidaritas-Nya, tidak hanya dengan manusia, melainkan juga dengan seluruh alam semesta yang dicipta-Nya. ${ }^{11}$

Pada waktu pola hidup pertapa populer (abad IV), beberapa orang Kristen berusaha "meninggalkan dunia", mencari perlindungan di padang gurun dan gua agar mereka tidak melihat alam, sehingga mudah berpikir mengenai keilahian. Orang bersembunyi di dalam gua agar tidak melihat langit yang biasanya berisi cerita dewa-dewi. Para biarawan/biarawati menutup diri di biara untuk menemukan Allah dalam teks-teks suci, dan dalam perayaan, serta nyanyian Gregorian selama berjam-jam, dan di jalur kontemplasi. Diyakini bahwa pengalaman rohani berada di luar (beda dengan) kehidupan harian manusia yang berada bersama dengan hal duniawi (ciptaan). ${ }^{12}$

Ide dan keyakinan tersebut ikut menyebabkan alam semesta kehilangan sifat simbolis dan unsur sakramental. Kurang disadari bahwa alam semesta bisa juga menampakkan keilahian (transparansi). Akibatnya beberapa manusia tidak tahu dengan baik tentang benda-benda, bahkan menganggap bahwa benda dunia tidak penting dan tidak bisa digunakan untuk mengenal Allah. Pemahaman seperti ini mengakibatkan gagasan yang keliru tentang ciptaan dan tentang Allah Pencipta yang hadir di dunia bersama ciptaan-Nya. Dengan inkarnasi jelas bahwa Allah berada bersama ciptaan-Nya. Dengan inkarnasi Sang Sabda tetap berdaya cipta, sehingga ciptaan: bintang, gunung, tumbuhan, hewan dan lain-lain menjadi indah karena didiami Allah.

\footnotetext{
${ }^{10}$ L. Boff, Jeritan Bumi..., hlm. 232, 246.

11 B.H.T. Prasasti (ed), Lingkungan Hidup ..., hlm. 130.

12 L. Boff, Jeritan Bumi..., hlm. 271-272.
} 
Semua ciptaan menjadi sumber dan teman berada dan teman belajar manusia untuk mendalami keberadaan Pencipta dan ciptaan-Nya.13

\section{Natal di Greccio}

Fransiskus dari Assisi ${ }^{14}$ memiliki cara tersendiri dalam mendalami peristiwa inkarnasi. Menurut Celano Fransiskus meminta sahabatnya untuk mempersiapkan kandang Natal hidup ${ }^{15}$ dengan "Bayi Yesus" yang lahir di Betlehem, berbaring di palungan di atas jerami di antara lembu dan keledai. ${ }^{16}$ Alasan Fransiskus membuat kandang Natal demikian agar dengan mata kepala dia dan saudara-saudaranya melihat "Bayi Betlehem" dengan keadaan pahit dalam kandang. Hal ini memesankan rasa iba akan Kristus yang lahir di Betlehem dalam kehinadinaan. ${ }^{17}$ Pada pesta Natal Fransiskus mengajak pemerintah dan masyarakat agar melindungi burung-burung dan tidak mengejar, memburu dan merusak margasatwa. Peristiwa Natal dikaitkan dengan kesadaran ekologis. Tuhan yang lahir sebagai manusia di bumi bukan hanya bagi manusia tetapi juga bagi seluruh ciptaan yaitu manusia, hewan, tumbuhan dan ciptaan lain. Dengan peristiwa Natal, Kristus mengilahikan manusia dan semua makhluk di alam semesta. Sehingga menurut Fransiskus, bukan hanya manusia patut berpesta waktu Natal tetapi juga hewan dan segala makhluk, serta ciptaan lain yang diyakininya bersaudara dalam Rahim Bapa Yang Maha Besar (Maha Rahim). ${ }^{18}$

Secara intuitif dan tanpa pelatihan teologis, Fransiskus menemukan bahwa dunia ini tidak bisu, hutan ikut menyanyikan lagu Natal; dunia bukan tanpa kehidupan, tidak kosong; ia berbicara dengan gerakan, dengan cinta, didukung oleh Keilahian. Dia yakin bahwa Yang Kudus tinggal di bumi. Fransiskus mengalami bahwa semua yang ada berada dalam Allah dan Allah hadir di dalam semua yang ada. Dia mengalami

${ }^{13}$ L. Boof, Jeritan Bumi..., hlm 251.

14 Fransiskus sebagai pelindung lingkungan hidup dinyatakan oleh Paus Yohanes Paulus II pada tahun 1979. Penghayatanya bersaudaraberasaudari dengan sesama ciptaan tertuang dalam lagu yang digubahnya yaitu Gita Sang Surya.

15 Tradisi Kandang Natal diperkenalkan oleh Fransiskus dari Assisi.

16 Thomas dari Celano, St. Fransiskus dari Asisi, Riwayat Hidup yag Pertama dan Riwayat Hidup yang Keudua (Jakarta, Sekafi, 1984), no. 84-87; untuk berikutnya sumber ini akan disingkat menjadi 1 Celano.

171 Celano no. 84.

181 Celano no. 85, 87. 
bahwa alam semesta memiliki ciri sakramental. Bumi ini berisi gerakan pergaulan ilahi, dan menjadi tempat seseorang bernafas, merasa, berpikir, dan mengalami Yang Ilahi dan kekuatan-Nya. ${ }^{19}$

\section{Bumi Baru}

Penghayatan yang baik dan benar tentang bumi dan isinya menjadikan bumi tetap baru. Bumi yang sama menjadi baru dengan memperhatikan perlindungan pelbagai makhluk hidup bersama dengan habitat mereka. Manusia dipanggil untuk menata ekologi agar bumi baru tersedia dan terawat untuk generasi mendatang sesuai dengan rencara Allah Pencipta. ${ }^{20}$

Cara manusia menata dan memperlakukan lingkungan mempengaruhi cara manusia memperlakukan diri sendiri, demikian pula sebaliknya cara manusia memperlakukan diri mempengaruhi caranya memperlakukan lingkungan. Perhatian pada manusia perlu (bukan antroposentrisme) dan sikapnya menjadi sorotan penting, karena manusia yang dicipta menurut Gambar Allah-lah yang mampu berperan untuk memelihara dan melindungi nilai dasar hidup. Peran ini memberdayakan manusia untuk dengan serius meninjau kembali gaya hidup yang di banyak bagian dunia cenderung ke ara hedoisme, konsumerisme. Bumi menjadi baru kalau terjadi perubahan mentalitas dan gaya hidup baru yang menonjolkan kebenaran, keindahan, kebaikan bersama semua ciptaan. ${ }^{21}$

Rasul Paulus menginspirasi manusia dalam menata relasi manusia dengan keseluruhan ciptaan. "Sebab Ia telah menyatakan rahasia kehendak-Nya kepada kita sesuai dengan rencana kerelaan-Nya, yaitu rencana kerelaan yang dari semula telah ditetapkannya di dalam Kristus sebagai persiapan kegenapan waktu untuk memepersatukan di dalam Kristus sebagai Kepala segala sesuatu, baik yang di sorga maupun yang di bumi." (Ef 1, 9-10). Nabi Hosea mengingatkan umat Allah, bila manusia mengingkari rencana Pencipta, ia mengakibatkan gangguan yang berpengaruh atas tatanan ciptaan lain. Bila manusia tak berdamai dengan Allah, maka bumi sendiri tidak dalam damai, "Sebab itu negeri ini akan berkabung, dan seluruh penduduknya akan merana; juga

\footnotetext{
${ }^{19}$ L. Boof, Jeritan Bumi..., hlm. 272.

${ }^{20}$ B.H.T. Prasasti (ed), Lingkungan Hidup ..., hlm. 104.

${ }^{21}$ B.H.T. Prasasti (ed), Lingkungan Hidup ..., hlm. 159.
} 
binatang-binatang di ladang dan burung-burung di udara, bahkan ikanikan di laut akan mati lenyap" (Hos.4, 3).22

Allah menulis hukum di alam yang dibaca oleh akal budi manusia. Pengenalan manusia akan hukum alam tersebut menuntun manusia dan memampukannya untuk menghormati rencana Allah, yaitu kebaikan manusia dan ciptaan lain. ${ }^{23}$ Allah menganugerahkan ciptaan lain bersama manusia, agar manusia menjaga dan memeliharanya. "Tuhan Allah mengambil manusia itu dan menempatkannya dalam taman eden untuk mengusahakan dan memelihara taman itu" (Kej 2, 15) Dunia ini indah, mendorong manusia untuk mengagumi dan menikmatinya, tetapi juga mengusahakan, memelihara, dan mengembangkannya. ${ }^{24}$

Di bumi baru harus ditanamkan tanggung jawab ekologis yang lebih luas dan lebih mendalam. Manusia harus mendengarkan bahasa alam dan menanggapinya. ${ }^{25}$ Masa depan yang baik untuk umat manusia hanya tercipta bila semua orang berusaha memiliki gaya hidup bertanggung jawab terhadap ciptaan. Kehidupan yang indah di bumi ini bukan akibat dari evolusi buta dan irasional, melainan merupakan perkembangan yang mencerminkan kehendak kreatif Pencipta dan keindahan serta kebaikan-Nya. ${ }^{26}$

Secara bersama hendaknya dijalankan pendidikan yang bertujuan menciptakan suatu "kewarganegaraan ekologis". Warga negara ekologis memiliki gaya hidup yang peka pada pelestarian lingkungan. Pelestarian itu dijalankan melalui tindakan kecil sehari-hari secara konsisten dan kontinu sehingga pelan-pelan terbentuk keyakinan bahwa kehidupan dan semua yang ada di bumi ini sungguh berharga dan bernilai pada dirinya. ${ }^{27}$

\section{Bumi Rumah Kita bersama}

"The earth was created by God to be our home, as the Book of Genesis says it was, that we humans are 'made of earth' that we are by nature earthly creatures and that the earth, our home, has a future that we can

\footnotetext{
22 B.H.T. Prasasti (ed), Lingkungan Hidup ..., hlm. 38.

${ }^{23}$ B.H.T. Prasasti (ed), Lingkungan Hidup ..., hlm. 74.

24 B.H.T. Prasasti (ed), Lingkungan Hidup ..., hlm. 83

${ }^{25}$ B.H.T. Prasasti (ed), Lingkungan Hidup ..., hm. 177.

${ }^{26}$ B.H.T. Prasasti (ed), Lingkungan Hidup ..., hlm. 185-186.

27 Paus Fransiskus, Ensiklik, Laudaro Si, tentang Perawatan Rumah Kita Bersama (Jakarta: Obor, 2015), no. 211-213.
} 
responsibly determine" 28 Allah memilih tinggal di bumi ciptaan-Nya. "The earth was made to be the home of God." 29 Pencipta dan yang dicipta saling mengasihi di bumi rumah bersama. Kebersamaan yang didiami Allah adalah kebersamaan saling mengasihi. "Dalam hal inilah kasih Allah dinyatakan di tengah-tengah kita yaitu, bahwa Allah telah mengutus Anak-Nya yang tunggal ke dalam dunia, supaya kita hidup oleh-Nya." (1 Yohanes 4, 9)

Paus Benediktus VI mengajak manusia secara bersama untuk memelihara bumi. "Keluarga memerlukan rumah, lingkungan yang sesuai untuk mengembangkan relasi yang pantas. Untuk keluarga manusia rumah itu ialah bumi, lingkungan yang diberikan Allah Pencipta untuk didiami dengan kreativitas dan tanggng jawab. Kita harus merawat lingkungan: ia dipercayakan kepada manusia untuk dilindungi dan dikelola dengan kebebasan bertanggung jawab, dengan kesejahteraan semua sebagai tolok-ukur tetap".30 Paus Fransiskus, "Sebagai manusia kita semua bersatu sebagai saudara dan saudari dalam suatu ziarah yang mengagumkan, terjalin oleh kasih yang Allah tunjukkan bagi setiap makhluk-Nya dan yang dengan kasih sayang yang lembut menyatukan kita juga dengan saudara matahari, saudari bulan, saudari air dan ibu pertiwi." 31

Fransiskus mendengar jawaban dari Kristus inkarnator yang tersalib di Gereja San Damiano, "Fransiskus pergilah dan perbaikilah rumah-Ku, yang seperti kau lihat bobrok seluruhnya ini!" 32 Rumah yang dimaksud bukan hanya gereja tetapi juga bumi, rumah bersama segenap ciptaan. Bagi Fransiskus seluruh bumi menjadi biara. Fransiskus mengalami dirinya dan segenap ciptaan lainnya bersaudara dalam Rahim Bapa Yang Maha Besar, dan sekaligus satu keluarga dalam satu rumah yang sama, yakni rumah bumi. ${ }^{33}$ Kekerasan di antara anggota keluarga bersaudara manusia tidak pernah dibenarkan, dan hal ini berlaku untuk bersaudara dengan ciptaan lain. Dengan melihat matahari, sinar, angin,

${ }^{28}$ C.M. Murphy, At Home on Earth..., hlm. 3..

${ }^{29}$ C.M. Murphy, At Home on Earth..., hlm. 6.

${ }^{30}$ B.H.T. Prasasti (ed), Lingkungan Hidup..., hlm. 153.

${ }^{31}$ Paus Fransiskus, Ensiklik Laudato Si, no. 92.

32 Bonaventura, Riwayat Hidup St. Fransiskus, Kisah Besar, diterjemahkan oleh Y. Wahyosudibyo (Jakarta: Sekafi, 1990), hlm. 5.

331 Celano no. $77,81-82$. 
udara, tanaman, dan umat manusia, Fransiskus mengungkapkan ekologi batinnya. ${ }^{34}$

Rumah kita bersama akan segar dan penghuni akan damai kalau pilihan-pilihan politis, ekonomi, pengembangan teknologi, dan promosi ekowisata memprioritaskan kebenaran, kebaikan, dan keindahan ciptaan. ${ }^{35}$ Keselamatan definitif yang Allah tawarkan kepada semua umat manusia melalui Putra-Nya tidak terlaksana di luar dunia ini. Dunia menjadi dunia yang dibarui karena Yesus masuk ke dunia, dan menjadi Penebus Dunia. (2 Ptr 3, 10-13).

Peristiwa Natal, Allah memilih bumi menjadi tempat tinggal-Nya mengajak manusia untuk semakin menancapkan akar kebersamaan di bumi rumah bersama. Gagasan Jay B. Mc Daniel memperkaya pemahaman. "Even as we recognize our galactic connections, our natural home is the Earth." 36 Dia menawarkan 8 ide menarik agar bumi ini menjadi tempat hidup berakar secara bersama. "We can be more rooted in the Earth 1)by enjoying a sense of place with respet to our local habits; 2) by revering individual animals as subjects in their own right; 3) by being respectful of and awed by the planet as whole; 4) by enjoying openess to our own bodies; 5) by becoming inwardy silent; 6) by feeling the pain of the world, both human and nonhuman; 7) by coming to terms with our own inner violence, which is part of earthly existence; and 8) by recognizing our call from Holy Wisdom to overcome this violence and be peacemakers in a broken world." 37

\section{Penutup}

"Theology always tends to focus all of its light on the process of the Incarnation, the passage of the Son of God from eternal existence to temporal existence." 38 Perayaan Natal merupakan momen indah untuk menyadari bahwa Pencipta yang bereksistensi eternal bereksistensi temporal dengan memilih bumi ciptaan-Nya menjadi tempat tinggalNya. Dengan pilihan Allah ini bumi menjadi rumah bersama Pencipta dan ciptaan-Nya. Kehadiran Allah di bumi, menjadikan bumi dan isinya berciri sakramental. Orang beriman dipanggil untuk memelihara alam

\footnotetext{
${ }^{34}$ L. Boff, Jeritan Bumi..., hlm. 280, 285, 286, 288.

35 B.H.T. Prasasti (ed), Lingkungan Hidup..., hlm. 95, 126.

${ }^{36}$ C.M. Murphy, At Home on Earth..., hlm. 43.

37 Jay B. McDaniel, With Roots and Wings, Christianity in an Age of Ecology and Dialogue (New York: Orbis Books 1995), hlm. 43.

${ }^{38} \mathrm{~J}$. Gallot, Who is Christ?..., hlm. 37.
} 
ini sebagai tempat Yang Ilahi. Kehadiran kreatif Pencipta di bumi ini makin transparan kalau manusia merealisasikan partisipasinya memelihara serta membarui bumi sebagai rumah bersama untuk Allah Pencipta, manusia ciptaan, dan ciptaan lain.

$$
===0000====
$$

\section{DAFTAR PUSTAKA}

Boff, Leonardo. Jeritan Bumi, Jeritan Penderitaan, Medan, Bina Media Perintis, 2008.

Bonaventura. Riwayat Hidup St. Fransiskus, Kisah Besar, diterjemahkan oleh Y. Wahyosudibyo, Jakarta, SEKAFI, 1990.

Galot, Jean. Who is Christ?, A Theology of the Incarnation. Roma, Gregorian University Press, 1980.

Prasasti, Bernadeta Harini Tri (ed). Lingkungan Hidup, Dokpen KWI, 2014.

McDaniel, Jay B. With Roots and Wings, Christianity in an Age of Ecoogy and Dialogue, New York, Orbis Books, 1995.

Murphy, Charles M. At Home on Earth, Foundations for a Catholic Ethic of the Environment, New York, The Crossroad Publishing Company, 1989.

Paus Fransiskus. Ensiklik Laudato Si', tentang Perawatan Rumah Kita Bersama, Jakarta, Obor, 2015.

Sinaga, Raidin. "Cur Verbum Capax Hominis, Asalan Inkarnasi Sabda menurut St. Thomas Aquinas", Logos, vol. 6, no. 1, Juni 2008.

Thomas dari Celano, St. Fransiskus dari Asisi, Riwayat Hidup yag Pertama dan Riwayat Hidup yang Kedua, Jakarta, SEKAFI, 1984. 